\title{
DETERMINATION AND RESEARCH OF THE MENTAL HEALTH DYNAMICS AMONG TEACHERS OF HIGHER EDUCATION WITH DIFFERENT PLACES OF PROFESSIONAL ACTIVITY
}

Tetiana Perepeliuk $^{1}$, Sergsii Penzai ${ }^{2}$, Natalia Pikovets ${ }^{3}$

${ }^{1}$ Candidate of Psychological Sciences, associate professor of the Department of Psychology, Pavlo Tychyna Uman State Pedagogical University, 20300, Ukraine, Uman, Sadova St., 2, Ukraine, ${ }^{2}$ Candidate of Sciences from Physical Education and Sport, teacher of Department of Sporting Disciplines, Pavlo Tychyna Uman State Pedagogical University, 20300, Ukraine, Uman, Sadova St., 2, Ukraine, ${ }^{3}$ Post-Graduate Student, Pavlo Tychyna Uman State Pedagogical University, 20300, Ukraine, Uman, Sadova St., 2, Ukraine.

Email: ${ }^{1}$ Perepeliuk_T@ukr.net, ${ }^{2}$ Penzai_S@ukr.net, ${ }^{3}$ N_Pikovets@ukr.net

\section{Article History: Received on $25^{\text {th }}$ July 2019, Revised on $01^{\text {st }}$ September 2019, Published on $13^{\text {th }}$ October 2019}

\begin{abstract}
Purpose of the study: The article deals with the problem of teacher burnout of higher education institutions in the process of carrying out his professional activity. Over rapid pace of life and neglecting own needs, people often make people who, in addition to endless challenges and obsessive ideas, do everything quickly and thoroughly, leading to the emergence of a syndrome of emotional (professional) burnout.
\end{abstract}

Methodology: The data of this research particularly are Sharabi's works published during 1980s as crucial period of his intellectual journey.

Results: The article reveals the results of an empirical study aimed at identifying the dependence of mental burnout on the length of professional experience. The research was conducted using questionnaire O. Rukavishnikov's "Definition of mental burnout" and questionnaires for specialists (author M. Kokun). The indexes of mental burnout among teachers with different pedagogical experiences are determined. It was found that the symptoms of mental burnout take place both at the beginning of and during the professional activity, and thus the tendency of reducing the tendency to mental burnout after 20 years of work in the specialty is traced. The high indicators of the professional motivation phase have been received, which may indicate higher expectations of teachers about the profession in general and the work in progress, in particular.

Applications of this study: This research can be used for the universities, teachers, and students.

Novelty/Originality of this study: The urgency of the choice of this problem is conditioned by the fact that frequent changes in the field of higher education in recent years have raised demands both on the professional competence of the teacher and on his personal component. Those or other forms of personally-professional deformations of the teacher reflected in his interaction with students and colleagues and may have a destructive tone in communication, attitude to the subject, assessment of their own results.

Keywords: mental health, professional burnout, professional experience, psycho-emotional exhaustion, personal detachment.

\section{INTRODUCTION}

Professional activity, occupying the overwhelming part of human life, appears to be an important psychological factor in his health, and hence in professional health, and can have both a positive and a negative impact on the development of his personality. In recent years, socio-political, economic and cultural changes have taken place in the country, which, in their turn, put new and complicated requirements for the employees of educational institutions: the teacher must possess not only sufficient professional knowledge but also to be a man of broad erudition, high spirituality, informational and a communicative culture capable of motivating students. Such an effect on the psychological state of teachers can lead to the emergence of emotional stress and, subsequently, the development of a significant number of professional stress, which leads to a deterioration of their mental health. At the same time, emotional problems, personal and professional deformations of a teacher of a higher education institution have a significant impact on his professional activity, personal and professional implementation and self-realization, which can hinder his development. Berezovska, L.I. (2015).

In the light of the changes that have taken place in the field of higher education in recent years, the problems of psychological provision of professional health of scientific and pedagogical workers in higher education institutions are very relevant and, at the same time, are not sufficiently developed in the context of scientific psychological literature and modern educational practice. Belyaeva, E.F. \& Zubkova, L.M. (2010).

Mental health is the basis of the productivity of all aspects of professional activity and the general well-being of a person, contributes to the harmonious development of personality and the achievement of professionalism. A professional in the broad sense has high indicators of professional activity, professional and social status, dynamically developing, the system of personal and activity normative regulation. Belyaeva, E.F. \& Zubkova, L.M. (2010). 
Professionalism as an integral characteristic of a person, a subject of a qualified activity, reflects its ability to successfully (that is, according to the criteria of productivity, quality, reliability of work, with optimal psychophysiological costs) to solve professional tasks. Gnuskina, G.V. (2016).

A professional, notes, is constantly aimed at self-development and self-improvement, on a new personality and professional achievements that have a significant social and positive significance. The researcher discloses the content of this concept not only as an achievement of high professional results but also in a broader context - as the success of human realization in life.

In particular describes the professionalization of the teacher as a complex process of active interaction of the individual and the professional environment, a purposeful, conscious process of personal acceptance of the content of professionalpedagogical activity, which greatly ensures the efficiency of scientific and pedagogical activity, preservation of psychoemotional health of the individual and personal satisfaction with professional self-realization. The current changes in higher education institutions, according to the author, are due to the need to respond to trends related to the orientation of the education system to the needs and demands of society, aimed at the development of the institution and its effective functioning. The purpose of the institution of higher education is to provide the conditions necessary for a person to receive higher education, to train highly skilled specialists in accordance with the modern labor market. The high school in this process is constantly experiencing the transformation of the structure, the change of functions, the search for new methods of teaching and control of knowledge, the attraction of effective innovative activities, etc. Accordingly, teachers of higher education institutions should respond quickly to changes in the functioning of the educational institution, to create new ways and methods that will help to effectively implement and use innovations in the educational and scientific spheres. This, in turn, requires a scientific and pedagogical worker of the corresponding psychological state, which will comprise such components as a feeling of satisfaction from the work performed, communication and interaction with students, colleagues and administration, the desire and the feeling of their own self-efficacy and self-realization, and, of course, proper level of physical and mental health. That is, it refers to the professional health of the teacher as a component of mental health.

The consequences of excessive and prolonged negative effects of risks (fatigue, emotional devastation, ever-increasing flow of information, intensification of interpersonal communications, etc.) can become signs of a variety of violations of professional health and, most importantly, the destruction of individual senses of professional life.

Professional health risks are considered as a potential possibility of influencing the probable factors or aggregate of factors that cause certain damage or severely violate the effective implementation by a specialist of professional activity, business communication and the realization of a professional career and may result in the development of distorted attitudes of a specialist to their own professional health a teacher.

The development of the personality of the profession is inevitably accompanied by changes in its structure, when, on the one hand, there is an intensification and intensive development of qualities that contribute to the successful implementation of the activity, and on the other - the change, suppression and even destruction of structures that are not involved in this process. If these professional changes are regarded as negative, that is, those that violate the integrity of the individual, remove its adaptability and stability, then they should be considered as professional deformation.

The state of mental health (illness), in turn, has an impact on the professional activity of the teacher: contacts with students and colleagues can become formal, develop a tendency to conflict, there is a sense of their own professional incompetence, etc. In this case, it is a question of the probability of professional stress, and, consequently, of professional (emotional) burnout. The analysis of scientific literature makes it possible to state that professional burnout of a person is mental, emotional and physical exhaustion that develops as a result of long-term professional stress.

Given the widespread recognition that "teacher quality" is one of the most influential factors determining the achievement of students, the concern of this problem, both Ukrainian and foreign scientists can predict that the prevention of burnout of the teacher should become one of the most important areas of global educational policy. Dem'yanchuk, R.V. (2015).

The phenomenon of professional burnout is quite common among representatives of different professions, especially those that involve working with people. The professional activity of a teacher belonging to socio-occupational professions is rather stress-related and can lead to professional burnout. the analysis of the content and individual manifestations of the syndrome shows that professional burnout has a rather complicated structure, that is, many symptoms that each employee of educational organizations can manifest in different ways, taking into account the specific circumstances of his professional and personal life. Among the first symptoms that arise from employees of educational organizations, they differ in general feeling of fatigue, hostile attitude to work, general uncertain feelings of anxiety, and perceptions of work as constantly becoming more complex and less effective. Serious manifestations of professional burnout are behavioral changes and rigidity (both external and internal). The rigorous educator is closed to change because it requires energy and risk, which is a great threat to the already exhausted personality. An employee of an educational organization that is experiencing the effects of a professional burnout syndrome can try to overcome the situation, avoiding colleagues, physically and thinking distantly from them. This can be manifested, in particular, through communicating with impersonal 
methods with colleagues, reducing their own involvement in contacts with them, eventually the worker becomes depressed and begins to perceive the situation as "hopeless", and may also leave his post or change his profession altogether.

Investigating the risks of professional health, distinguishes four groups of risks, which determine the following factors: destructive communications characterized by the author as dominant (criticism, mobbing, negative relationships with participants in the educational process, conflicts, authoritarianism, etc.); destabilizing organization of professional activity (occupational activity depletes physically and morally, excessive load, multiple tasks at once, chronic fatigue, the need to stay after work for the current professional tasks, the frequency of changes, reconstruction, innovations, etc.); destructions of professional self-affirmation (too high demands on oneself or others, zeal to oneself or on the other, constant comparison of oneself with other specialists in the context of the most successful attitude to the pole, very high responsibility); demotivators of labor productivity (emotional exhaustion, negative evaluation of labor, monotony while performing professional tasks, negative assessment of himself as a professional and personality). Understanding the risks of professional health sets the teacher's behavior in relation to his own professional health, is an integral part of the image of "I am a professional", it's content and professional self-help. Kenan, K. X. (2018).

In the model of professional stress, the workers of educational organizations Karamushka presents his development as follows: socio-economic and socio-psychological factors are due to the peculiarities of the working environment of the educational institution and the complex situations that occur in the activity of the teacher, modeling a particular stress environment; physiological changes and psychological problems of a person (symptoms) arise depending on the intensity of the above three conditional blocks of factors and individual personality of the employee .

Professional burnout has serious negative consequences, both for the activity and personality of the individual and for the level of activity and organizational behavior of the entire organization Gnuskina testifies in his study. In relation to an individual, it is a question that professional burnout leads to the disintegration of various psychological spheres of the individual (motivational, emotional, cognitive, behavioral, socio-psychological, etc.), reducing the adaptive capacity of the individual. In this case, the emotional sphere undergoes the greatest losses, the disorder in which "further" disintegration mechanisms are launched, which "destroys" the person. The presence of such disintegrations leads to a decrease in human mental activity, a positive perception of oneself and the surrounding social environment, "distorts" the further professional and life prospects of the individual. Gnezdilov, A.V. (2004).

Regarding the organization of work, we can talk about the following negative consequences of professional burnout: reduction of disability; high conflict of personnel and heavy atmosphere in the institution; lack of cooperation among staff; reduced motivation of labor; growing sense of dissatisfaction with work; manifestations of negativism regarding the role or function of the department; the professional dependence of the staff from the management, which manifests itself either in an increased and inadequate critical attitude to management, or in a sense of helplessness without active assistance from management; Inadequately high turnover of frames. Bahremand, A. (2015).

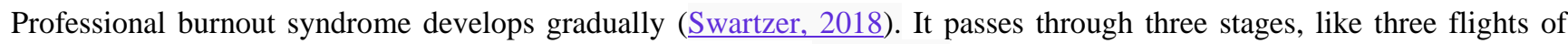
stairs into the depths of professional unsuitability, according to Alkhateeb.

The first stage begins by muffling emotions, smoothing the sharpness of feelings and freshness of experiences. The specialist unexpectedly remarks: everything seems to be okay for now, but ... it's boring and empty to the soul.

Positive emotions disappear. There is some detachment in relation to family members.

There is a state of anxiety, dissatisfaction. Returning home, more often you want to say: "Well, do not meddle with me, leave me alone!"

In the second stage, there are misunderstandings with students. A professional begins, in the circle of his colleagues, to speak disdainfully about some of them. Gradually hostility manifests itself in the presence of students. Initially, it is a pentup antipathy, and then outbreaks of irritation. Such behavior of a professional specialist is a manifestation of selfpreservation, which is not realized by him, during communication, exceeding the level safe for the organism.

In the third stage, ideas about the values of life are dulled. The emotional attitude to the world "flattens", a person becomes dangerously indifferent to everything, even to his own life.

Out of habit, such a person can still maintain external respectability, but his eyes lose the shine of interest in anything, and an almost physically tangible cold of indifference settles in his soul.

The purpose of the article is to find out the presence of mental burnout among teachers of a higher education institution with a different professional experience.

Tasks:

- Determine the index of mental burnout for teachers with different professional experiences.

- To carry out a comparative analysis of the quantitative indicators of the manifestation of mental burnout in the phases of mental exhaustion, personal discretion, and professional motivation. 
- Find out the dynamics of manifestation of symptoms of mental burnout in different periods of professional activity.

\section{LITERATURE REVIEW}

The syndrome of "mental" or "emotional" burnout, becoming the subject of a broad scientific analysis of foreign authors since the 60s last century, has not lost its relevance in the conditions of the modern reality. This is evidenced by a large

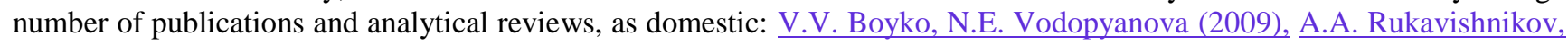
E. Starchenkova, L.I. Antsyferova, T.V. Kopylova, A.B. Leonova, S.G. Nikiforov, et al.

In particular, researchers pay great attention to the definition of the essence, description of the structure, causes, manifestations, and development of burnout syndrome.

For the first time, scientists told the world about this disease at the beginning of the second half of the 20th century, and, moreover, this disease was considered for a long time to be such a form of a viral infection. In the 1970s, some features of this disease were noticed by scientists - they suffered most from people who could be attributed to such social groups as the intelligentsia, and this disease was not uncommon among family members of such people.

Professional burnout syndrome is not a medical diagnosis and does not mean that such a condition is inherent in every person at a certain stage of his life or career. However, one can name a number of specialties whose owners are more likely than others to be at risk of professional "burning out", because they use the resources of their psyche in working with people (Seidel, 2014).

In the mid-70s of the last century, such a concept as "burnout" was first used. And this definition was used to describe the psychological state of people who were closely associated with customer communication, which proceeded in an emotionally overloaded environment. Such an atmosphere was characteristic of their workplace, where they spend most of their lives (Gnezdilov, 2004).

In domestic psychology, the development of the problem of psychological burnout began to focus on relatively recently, from the last decade of the 20th century; this has been historically associated with the introduction of market relations and the intensification of human labor in society.

But in foreign psychology, this phenomenon began to be studied several decades earlier. The formation of psychological burnout, caused professionally, is most pronounced in the professions of the social sphere, where the main object of labor is a person, his development problems.

In the early 80s, Christina Maslach developed a scientific approach to studying the issue of professional burnout, which resulted in the creation of the MBI methodology, which is a tool for measuring occupational diseases such as burnout. This process is characterized by three concepts - cynicism, reduced work efficiency, and emotional exhaustion.

In the late 90 s of the twentieth century, psychological burnout under the name of "burnout syndrome" was studied in various areas of human professional activity in Russian psychology. The features of the work of teachers, psychologists, doctors, social workers were studied. It was found that all these "helping" professions are united by the presence of stress factors that increase the risk of mental burnout.

Numerous studies show that the pedagogical profession is one of those that are more susceptible to the effects of burnout. This is due to the fact that the professional work of a teacher is distinguished by a very high emotional workload.

Modern society places high demands on the education system. Teachers, seeking to meet these requirements, are forced to continually improve the level of professional competence, which, in turn, already leads to physical and intellectual overloads.

Thus, the low level of remuneration forces many teachers and psychologists to take on the extra workload at school (a huge number of class hours), in kindergarten (two-shift work), and often additional work related to tutoring or caring for children. To all this, representatives of these professions often do not feel satisfaction from their activities: it seems to them that, despite all the efforts, the children with whom they work do not have enough knowledge of the necessary material.

Of course, job dissatisfaction can be caused by low wages, however, according to D. Greenberg (2002), high wages and good working conditions are not yet a guarantee of job satisfaction, since there are also motivational factors. These include the degree of difficulty of the assignments, the amount of work that will be positively evaluated upon completion, and others (Orel, 2001).

Overloading at work cannot but affect the personal life of specialists, and after all, the vast majority of teachers and psychologists in education are women. Raising their own children sometimes goes into the background, which is the reason for the formation of guilt, their own incompetence in matters of upbringing, apathy, or, conversely, irritation and aggression directed at themselves or others (Koç, Hakan \& Dinçerol, Cem, 2013; Bill and Melinda Gates Foundation, 2014).

Thus, problems in the family, a violation of relationships with relatives and, first of all, with children can become a consequence of professional burnout. Professional burnout of the teacher, his emotional devastation, cannot but affect his 
activities in school and in kindergarten, because the atmosphere of indifference and tension brought by the teacher or educator negatively affects children, their motivation to learn and attitude towards the teacher (Zborovskaya, 2001).

Nevertheless, until the present time, in-depth research studies on the development of burnout among teachers, especially among high school teachers, are extremely few.

Increasing demands from society on the professional qualities of a higher school teacher, an objective increase in study load, labor intensity, psycho-emotional overload, high loads on the visual, hearing and voice apparatus, a large number of contacts during the working day, hyperdynamic makes this group of specialists even more vulnerable in relation to the development of mental burnout, due to professional activity (Fujo \& Dida, 2019).

From modern teachers of higher education are required not only competence in their field of knowledge and pedagogical skills, but also a high level of psychological knowledge and skills that allow them to maintain professional competence and efficiency in their activities.

On the other hand, psychological knowledge and skills, auto competence, enshrined in the structures of self-consciousness as the personal qualities of the teacher, can serve as a psychological condition for the prevention of professional burnout.

As the end results of the effect of burnout syndrome, the following diverse manifestations are most often considered: reduced efficiency and subjective satisfaction with work, loss of identification with the organization, negative attitude to work, dismissal from work, and deterioration of health. It is important to study the negative impact of the profession of a teacher in connection with the formation of his professional burnout and the increasing negative manifestation of this phenomenon in the properties of his personality. It may be noted as a consequence - a decrease in the effectiveness and quality of the teacher's impact on the audience (Novikova et al, 2018; Kenan, 2018).

Published data show that burnout syndrome, like other types of occupational stress, causes depressive moods, feelings of helplessness and meaninglessness of their existence, low assessment of their professional competence, which affects the performance of the teacher, leading to a decrease in the performance of professional activity and, as a result, burnout syndrome provokes a violation of labor discipline, an increase in the incidence of professionals.

Experiencing a sense of personal insolvency, indifference to professional activity, loss of previously significant life values leading to a decrease in the intrapersonal resources of a specialist, the development of psychosomatic disorders is often a consequence of the development of burnout caused by professional activity (Practical psychodiagnostics. Methods and tests, 1998).

Currently, the most studied are the two main phenomena of the destructive influence of the teaching profession on his personality: professional deformity and burnout syndrome.

At this time there is no definitive answer to the question of what is the main catalyst for the occurrence of burnout, and what is the main factor - the individual characteristics of a person or organizational characteristics. When studying this problem and constantly encountering cases of professional burnout, which is revealed in the course of personnel audit of personnel or when interviewing candidates for a vacant position, you have to look for the answer to the question: what caused the burnout in this particular case?

The search for the answer led to the approach of S. Maslach and M. Leiter, who suggested that burnout is the result of the discrepancy between the individuality and the work on which the employee works and performs official duties. Increasing this kind of inconsistency increases the likelihood that an employee's burnout process will occur.

Now the society is declaring the image of a socially successful person, this is the image of a self-confident person, independent and decisive, who has achieved career success. Therefore, many people try to conform to this image in order to be in demand in society. But to maintain an appropriate image, the teacher must have internal resources.

Research N.A. Aminova, L.G. Fedorenko (2003) proved that after 20 years, an overwhelming number of teachers experience emotional "burning", and by the age of 40 all teachers are burning down. In addition, even among beginning teachers, the degree of social adaptation was lower than that of patients with neurosis, which is manifested in behavior in incontinence, rudeness, insecurity, anxiety. Also, the profession of a teacher is one of the professions of the altruistic type, which increases the likelihood of burnout.

Pedagogical workers, constantly encountering the intensity and emotionality of human relationships, are forced to erect a kind of barrier of psychological protection from parents, students, colleagues, to become less empathetic, otherwise, they face emotional burnout. This should also include the psychological difficulties of receiving, unconditional communication, described by C. Rogers and E. Fromm (Orel, 2001).

Essentially, emotiongenicity lies in the very nature of pedagogical work, and the spectrum of emotions is very diverse. At the same time, the teacher who bears the burden of "communication" constantly has to be in the oppressive atmosphere of negative emotions, serve as a comforter, and then, on the contrary, a target for irritation and aggression. But our psyche by nature is designed so that we cannot remain indifferent to the manifestation emotions from others, as if we are "infected" with them. To this are added more and secondary experiences about other people's problems, especially children's, caused 
by the invisible, but perceptibly weighing burden of responsibility. The consequence of all this may be in addition to its own deterioration in human health and a steady decline in the impact of its work. The result is known: "Another one burned at work." In fact, professional burnout is long chronic stress.

Professional burnout is characterized by the emergence of a feeling of indifference to work, to colleagues (even if they used to be quite sympathetic to you) and in general to everything that happens. A person loses self-confidence, begins to blame himself for the lack of knowledge, experience, competence, and professionalism. Professional burnout syndrome is accompanied by physical symptoms.

Since negative emotions constantly accumulate, this can lead to a depletion of the body's emotional and energy resources. Exhaustion is expressed in increased fatigue, constant fatigue, sleep disturbances (insomnia), irritability, headaches, hearing and sight deterioration (which at first glance may seem unreasonable) (Gnezdilov,2004).

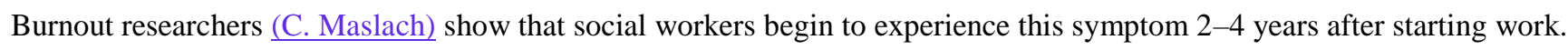
The tendency of younger people to burn out due to emotional shock that they experience when confronted with reality, often not meeting their expectations (Formalyuk, 1994).

Especially important is the study of the relationship of personality features and burnout (Formalyuk, 1994). Personal endurance is the ability of an individual to exercise control over life situations and to respond flexibly to various kinds of changes.

A close link has been found between professional burnout syndrome and the "locus of control". If a person, for the most part, accepts responsibility for events occurring in his life, on himself, explaining them with his behavior, character, abilities, then this indicates that he has an internal locus of control. If he has a tendency to attribute responsibility for all external factors, finding causes in other people, in the environment, in fate or in case, then this indicates that he has an external locus of control. Practically in the majority of works on this subject, a positive correlation is noted between the external locus of control and the components of burnout (Formalyuk, 1994).

K. Kondo refers to "burnout" as "workaholics" (who decided to devote themselves to the realization of working goals only, who found their recognition in the work before the self-forgetting). Persons who make excessive demands on themselves are most susceptible to burnout. In their presentation, a real specialist is a model of professional invulnerability and perfection. The personalities of this category associate their work with the mission, so they blur the line between work and personal life.

There are studies showing a link between marital status and burnout. They have a higher degree of susceptibility to burnout of persons (especially males) who are not married. And bachelors are more prone to burnout, even compared with divorced men. Most likely, this may be due to the simultaneous action of other factors. However, psychologists believe that professional burnout syndrome is more common in women than in men. Women are often inclined to more emotionally experience professional failures and problems in communicating with colleagues.

The development of burnout can contribute to uncertainty or lack of responsibility. At the same time, the independence of the teacher in their activities, the ability to make important decisions are an important point that adversely affects burnout.

Professional burnout syndrome is closely related to the fact that work can be hours-long, not properly evaluated, having an inaccurate content, requiring exceptional productivity or appropriate training, so that the nature of leadership from the superiors does not match the content of the work.

Almost all researchers show that increased workload, overtime work stimulates the development of burnout. Similar results were obtained between working hours and burnout since these two variables are closely related to each other. Breaks in work have a positive effect and reduce the level of burnout, but this effect is temporary: the level of burnout partially increases three days after returning to work and is fully restored after three weeks (Formalyuk, 1994).

The decisive role in preventing burnout is social support from colleagues, managers, family, and friends. Especially significant is the support of the administration. When stimulating workers, it is important (and this is noted by many researchers) not the absolute amount of remuneration, but its correlation with their own spent labor and the work of their colleagues, which is denoted as justice. In addition, researchers (Trunov, 1998; Formalyuk, 1994) emphasize the importance of such factors as feedback. "Our ignorance becomes a significant obstacle," writes A.N. Mokhovikov, - did we really help, as we often have no information about the further development of the situation. Tormented by doubts, we are doing "bad work": we excessively reflex, worry, turn aside, give up or bravely fight; and this somehow increases fatigue and apathy with time" (Formalyuk, 1994). Contribute to the occurrence of burnout direct deep contact with students and the severity of their problems.

N. Mokhovikov calls other factors of the onset of burnout syndrome: intrapersonal conflict and acute psychological stress. Professional burnout syndrome is a reaction to stressful effects (Trunov, 1998). V.V. Boyko believes that burnout represents the psychological defense mechanism developed by the individual in the form of complete or partial elimination of emotions in response to selected traumatic effects (Boyko, 1996). It is advisable to periodically check the extent to 
which the teacher has formed a psychological defense in the form of emotional burnout, this makes it possible to develop measures to prevent it.

Burnout is especially dangerous at the beginning of its development since a "burned out" teacher is usually not aware of his symptoms, and changes in this period are easier to notice from the outside. Burnout is easier to prevent than to cure, so it is important to pay attention to the factors contributing to the development of this phenomenon (Pak, 2016).

\section{MATERIALS AND METHODS}

Emotional, mental, and professional burnout is quite actively discussed in scientific circles. These categories are often used as synonyms or with some semantic modifications, as they often have similar characteristics.

In the article, we give the results of the empirical research. The psycho-diagnostic complex consisted of the methodology of O. Rukavishnikov "Definition of mental burnout", a questionnaire for specialists.

Teachers were asked to answer questions from the questionnaire to determine mental burnout. The method contains 72 questions, which are systematized into three independent scales (phases).

The phase of psycho-emotional exhaustion reflects the process of exhaustion of the emotional, physical and energy resources of a professional who works with people. It is manifested in reducing the emotional background, indifference or emotional over-saturation. Exhaustion is manifested in chronic emotional and physical tiredness, indifference and cold attitude towards people with signs of depression and irritation.

The phase of personal separation characterizes the specific form of social maladaptation of a professional who works with people. This phase is manifested in reducing the number of contacts, increasing irritability and intolerance in situations of communication, negativism in relation to other people.

The phase of professional motivation reflects the level of work motivation and enthusiasm for the work of altruistic content, which is measured by indicators such as productivity of professional activity, optimism, and interest in work, selfevaluation of professional activity and the degree of success in working with people. Manifestations of mental burnout in each of the phases are characterized on the interpersonal, personal and motivational levels. The methodology gives an opportunity to get the general level of mental burnout (the index of mental burnout), which is determined by the compilation of the obtained indicators in three scales.

The study also used the M. Kokun questionnaire to identify probable factors of mental burnout and obtain general information on the professional adaptation of teachers in an educational institution, the formation of their own professional position and style of activity, self-assessment of the level of professional achievements, the ability to self-design their own careers, I will enjoy the professional activities, interpersonal relationships in the team, emotional state and health. It was supposed that the answers to these questions would enable us to identify the probable socio-psychological causes of the revealed indicators of mental burnout and the direction of further psycho-corrective work with teachers.

The sample of the study consisted of teachers of the higher education institution of the second level of accreditation of the humanities. The number of samples is 78, of which 6 men and 72 women. For the experience of pedagogical activity:

1 - Up to 10 years - 26 people;

2 - Up to 20 years - 28 people;

3 - Over 20 years - 24 persons.

\section{RESULTS AND DISCUSSION}

Responses of the respondents to the questions of the questionnaire O. Rukavishnikov make it possible to state the presence of mental burnout in all three groups of respondents and to trace the degree of expression of indicators of mental burnout by multiple components (Table 1).

Table 1: Distribution of surveyed teachers by indicators the level of mental burnout

\begin{tabular}{|c|c|c|c|c|c|c|}
\hline & $\begin{array}{l}\stackrel{0}{0} \\
.0 \\
.0\end{array}$ & $\begin{array}{l}\text { Index } \\
\text { mental } \\
\text { burnout }\end{array}$ & & $\begin{array}{l}\text { f Psycho- } \\
\text { emotional } \\
\text { burnout }\end{array}$ & $\begin{array}{l}\text { Personal } \\
\text { detachment }\end{array}$ & $\begin{array}{l}\text { Professiona } \\
\text { l motivation }\end{array}$ \\
\hline$\frac{01}{2}$ & & Points & $\%$ & Points \% & Points \% & Points \% \\
\hline 1. & EL & $\begin{array}{l}31 \text { and } \\
\text { lower }\end{array}$ & 0 & $\begin{array}{l}9 \text { and } \mathbf{0} \\
\text { lower }\end{array}$ & $\begin{array}{l}9 \text { and } \mathbf{0} \\
\text { lower }\end{array}$ & $\begin{array}{l}7 \text { and } \mathbf{0} \\
\text { lower }\end{array}$ \\
\hline 2. & $\mathbf{L}$ & $32-51$ & 5,1 & $10-20 \quad 36$ & $10-16 \quad 18$ & $8-12$ 0 \\
\hline 3. & $\mathbf{A}$ & $52-92$ & 57,7 & $21-39 \quad \mathbf{3 3 , 3}$ & $17-31 \quad \mathbf{5 6 , 3}$ & $13-240$ \\
\hline 4. & $\mathbf{H}$ & $92-112$ & 16,7 & $\begin{array}{ll}40-49 & \mathbf{2 3} \\
\end{array}$ & $32-40 \quad 18$ & $25-31 \quad 5.1$ \\
\hline 5. & EH & $\begin{array}{l}113 \text { and } \\
\text { higher }\end{array}$ & 20,5 & $\begin{array}{l}50 \text { and } \\
\text { higher }\end{array}$ & $\begin{array}{l}41 \text { and } 7,7 \\
\text { higher }\end{array}$ & $\begin{array}{l}32 \\
\text { and }\end{array}$ \\
\hline
\end{tabular}


Notes: EL - extremely low, L - low, A - average, H - high, EH- extremely high.

The results of the survey allowed identifying $37.2 \%$ of respondents with a high and extremely high level of mental burnout. Based on the data obtained, we have the following distribution: $20.5 \%$ of respondents are high and $16.7 \%$ extremely high level of burnout. The most pronounced group is respondents with an average level of mental burnout $(57.7 \%) ; 5.1 \%$ - low. Extremely high and high rates were obtained on the scale of "Professional motivation" (94.9\% and $5.1 \%$ ). In other words, in fact, all respondents showed a high level of professional harassment, which entails enthusiasm, high self-esteem, and the desire to assert its significance. These indicators are further confirmed by the answers to the questionnaire, in which the respondents emphasized the importance of their work and satisfaction with it, aspiration and constant improvement of their own professional level. This tendency leads to the need to work beyond measure and, at the same time, to remain dissatisfied with their own results, loses the feeling of performing a significant amount of work, and, consequently, there are prolonged emotional experiences and psychological stress.

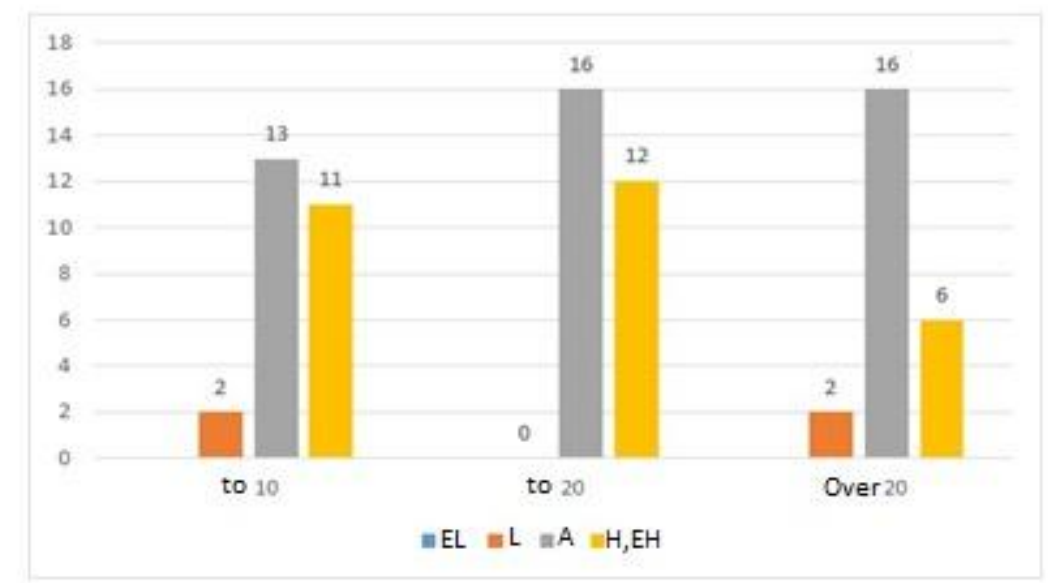

Figure 1: Scale levels of mental burnout.

The results of the questionnaire made it possible to find out that virtually all the respondents quickly entered the new role of a specialist after graduation and acquired sufficient experience for independent professional activity (from 2-3 months to 1 year). It is considered that they have a formed professional position: "partially" - 6 persons (7.8\%), "almost" - 18 (23\%), "yes" answered 54 respondents (69.2\%); the formed personal style of professional activity was defined as: "partially" - 8 persons (10.2\%), "almost" - 10 (12.8\%), "yes" answered 60 persons (77\%). The level of professional achievement was rated as: the average - $18(23 \%)$, the average - $32(41 \%)$, high - $28(36 \%)$. Evaluated the increase in their own professional level in recent times as: mostly unsuccessful 1 person (1.3\%), mediocre - $13(16.7 \%)$, successful - 64 (82\%). 11 persons interested in professional activity (14\%), strongly and very strongly - $67(86 \%)$.

The questionnaire made it possible to find out the degree of professional and socio-professional satisfaction of teachers. We believe that this factor significantly affects the mental health of the individual, and, therefore, the propensity to mental burnout.

Table 2: Professional and social-professional satisfaction of teachers

\begin{tabular}{|c|c|c|}
\hline Satisfaction & $\begin{array}{l}\text { Satisfies, more } \\
\text { satisfied }\end{array}$ & $\begin{array}{l}\text { More dissatisfied, } \\
\text { dissatisfied }\end{array}$ \\
\hline $\begin{array}{l}\text { Contents of the } \\
\text { profession }\end{array}$ & $96,2 \%$ & $3,8 \%$ \\
\hline Salary & $28,2 \%$ & $71,8 \%$ \\
\hline Career & $87,2 \%$ & $12,8 \%$ \\
\hline Social position & $64 \%$ & $36 \%$ \\
\hline
\end{tabular}

All respondents confirmed that they love their profession, constantly $58(74.4 \%)$ or periodically 20 (25.6\%) work to increase their own professional level. The vast majority of respondents have good relations with colleagues and management.

Among the components that characterize psycho-emotional exhaustion - a feeling of tiredness after a working day (Table 3). 
Table 3: Self-assessment of teachers' tiredness during the working day

\begin{tabular}{lll}
\hline \multicolumn{2}{l}{ Tired during the day } & \\
\hline $\begin{array}{l}\text { Extremely strong, } \\
\text { strong }\end{array}$ & Moderate & Not too much \\
\hline $28,2 \%$ & $53,8 \%$ & $18 \%$ \\
\hline
\end{tabular}

By rating their own health, the respondents replied that it was mediocre - $45(57.7 \%)$, well - 32 (41\%), only 1 person $(1.3 \%)$ called it bad. Thus, there is a tendency for the subjects to be tired during work, and their level of health requires attention and control.

Thus, indicators were found that, hypothetically, maybe the reason for the results of the level of mental burnout. Characteristics such as: interest, satisfaction, and love of the profession, aspiration for professional self-improvement can be further used as personal resources for carrying out preventive or corrective work with teachers.

The data obtained from the investigations, we compared with the results of other researchers. Thus, T. Koltunovich's analysis of the results of research by researchers on the connection between professional burnout with age and the experience of teachers shows that many of the data presented are highly controversial. So, M. Guberman thinks that the burnout of teachers reaches a peak between 7 and 12 years of professional activity and at the age of 30 to 45 years. B. Farber argues that teachers aged 33-44 are least likely to be burned out. B. Perlman, I. Hartman, K. Leytwood and others believe that higher levels of burnout are more common to young teachers, and for teachers with small and very long work experience (more than 25 years), the risk of burnout is lower. T. Katkova concludes that higher rates of burnout among teachers with experience of 10-15 years and in the age range of 29-39 years. According to N. Vodopyanova (2009) and O. Starchenkova, the positive relationship of burnout with age is due to the age-appropriate professional experience. However, in the age of 45-50, the age itself begins to affect the burnout, so it is often possible to transform this connection into the reverse. It is likely to assume that this reciprocal correlation is somehow associated with age-related changes, in particular, with a reassessment of values, personal and professional growth/depletion (Koltunovich, 2016; Suleri \& Cavagnaro, 2016).

In the studies of V. Ovsyannikova, it was found that the highest rates are teachers with work experience from 2 to 5 years and from 15 to 23 years. In the period from 15 to 25 years of pedagogical experience there is a sharp weakening of professional qualities, deforming qualitative behavioral and characterological properties of the teacher, which does not directly ensure its professional performance (Ovsyannikova, 2012).

Considering the age as a possible burnout factor, Polish researchers have not found a significant indicator of the level of burnout from the age of respondents. However, they are less optimistic, they believe, and, therefore, the first age group (20-35 years) is the most vulnerable among the three groups (20-35, 36-40 and 41-45) (Aouil, Leźnicka, JachimowiczWołoszynek \& Zaremba, 2011; Bahremand, 2015).

The lowest rates of burn-up fall on the work experience from 6 to 9 years and from 11 to 14 years. When starting to work, a teacher of higher education does not always get what he was expecting from work. Young teachers often encounter situations that have not been prepared. Therefore, the first years of work a young teacher adapt to the conditions and new requirements of teaching activities. During this period, most teachers are prone to manifestations of professional burnout.

Australian researchers studied the issue of perceiving the workload (the ratio of stress and rewards for the work done) by educators who began their professional careers with the burden of more experienced colleagues. The results showed that a significant proportion of the group of start-up teachers believed that they were working with high strain on their colleagues and regarding their perception of work remuneration. Although almost half of all respondents (48\%) said that they consider the efforts they are putting into their work, they are equal to the rewards they receive from performing work; more than a third $(39 \%)$ of respondents believe that their efforts in their work are more than the rewards received for the efforts made. When beginner teachers were asked to compare the efforts that they put into their work, they are believed to be invested by more experienced teachers at the same institution: $63 \%$ of respondents said they believe they should work tenser than their more experienced colleagues. Only $32 \%$ identified their workload roughly the same as with more experienced teachers, and less than $5 \%$ of respondents thought their workload was less. In addition, the study found that after two years after the teaching career, $12 \%$ of respondents indicated a serious intention to leave the profession as a whole, and almost a fifth of respondents indicated that they had significant doubts about the choice of education at university and later to pursue a pedagogical career (Goddard, \& Goddard, 2006; Iravani et al, 2015).

The results of the Greek scientists' research on this issue also show that young teachers show a higher level of emotional exhaustion and depersonalization than their elder colleagues. This reaction is probably due to the difficulty of young teachers to activate appropriate strategies to overcome them in order to reduce the professional stress caused by the difficulty of their work (Antoniou, Polychroni, \& Vlachakis, 2006).

Thus, the results of research by foreign scientists confirm the existing high risk of professional burnout and even the likelihood of leaving a professional career at the initial stage. 
Experience according to Polish researchers are among the factors that help to neutralize or cope with burns (Aouil, Leźnicka, Jachimowicz-Wołoszynek \& Zaremba, 2011).

Signs of burnout can be detected at any age, as evidenced by research by R. Demyanchuk, and, probably, with any pedagogical experience. The fact of the existence of single strong ties between the signs of emotional burnout, the age, and experience of teachers makes it possible to conclude on the more significant role of other factors contributing to its development. First of all, personal, as well as related to the conditions and content of professional activities (Dem'yanchuk, 2015).

\section{CONCLUSION}

The work of a teacher of a higher education institution belongs to a group of stress-related and professionally deforming. This phenomenon is conditioned both by social and individual psychological factors.

The phenomenon of mental burnout at the institution of higher education was investigated and an attempt was made to establish the relationship between the formations of professional stress, depending on the professional experience.

According to the results of diagnostic tasks, it was discovered that the symptoms of mental burnout are inherent to teachers, regardless of their professional experience: in all groups, a high level of symptoms of mental burnout is attested. The tendency towards the reduction of the manifestation of mental burnout with an increase in professional experience is traced, which is probably due to age-related changes.

The most pronounced symptom of mental burnout is professional motivation, which involves the teacher's overrepresented expectations of work.

The prospect of further research is to further study the relationship of mental burnout with professional expectations and develop a training program to prevent professional burnout from teachers.

\section{ACKNOWLEDGMENT}

The author confirms that the data do not contain any conflict of interest.

\section{REFERENCES}

1. Bahremand, A. (2015). The concept of translation in different teaching approaches and methods. UCT Journal of Social Sciences and Humanities Research, 3(1), 5-9.

2. Berezovska, L.I. (2015). Professional burnout of employees of modern educational organizations. Herald of Mukachevo State University, no1. 130-135. Retrieved from http://nbuv.gov.ua/UJRN/nvmdupp_2015_1_33

3. Belyaeva, E.F. \& Zubkova, L.M. (2010). Professional deformation of a teacher of higher education. Herald of scientific works of Kharkiv National University named after V. N. Karazin, no 24. Kharkiv. 25-32. Retrieved from https://periodicals.karazin.ua/pedagogy/issue/view/312

4. Gnuskina, G.V. (2016). Psychological factors of professional burnout from entrepreneurs. Kiev.

5. Dem'yanchuk, R.V. (2015). Psychological assistance to teachers with signs of emotional burnout: grounds and guidelines. Klinicheskaya $i$ spetsialnaya psihologiya, no 4(4). 12-28. Retrieved from https://psyjournals.ru/. https://doi.org/10.17759/cpse.2015040402

6. Dzuba, T.M. (2016). Professional health teacher: the risks of potential and devastating effects. Proceedings from All Ukrainian scientific practical conference: Achievements and prospects of the study of the phenomenon of health in modern psychological science. Vinnitsa: TOV Nilan-LTD. 66-72.

7. Maksimenko, S.D., Karamushka, L.M., Zhaichikova, T.V. et al. (2004). The syndrome of "burnout" and the professional careers of educational institutions: gender aspects. Kiev: Milenium.

8. Kenan, K. X. (2018). Seeing and the Ability to See: A Framework for Viewing Geometric Cube Problems. International Electronic Journal of Mathematics Education, 13(2), 57-60. https://doi.org/10.12973/iejme/2695

9. Kovrovskiy, U.G. (2013). Factors of professional burnout of the personnel of the operational and rescue service of the Ministry of Emergencies of Ukraine. Herald of Institute of Psychology named after G.S. Kostiuk NAPS of Ukraine, no 37. 262-265.

10. Koltunovich, T.A. (2016). Psychological conditions for the correction of professional burnout at the children's educational institutions. Ivano-Frankivsk.

11. Kruzheva, T.V. (2014). Professional self-realization: a system of concepts. Actual problems of psychology. Herald of Institute of Psychology named after G.S. Kostiuk NAPS of Ukraine, no 14.

12. Melnichenko, O.I. (2013). Psychological peculiarities of professional activity of teachers of higher educational institutions. 84-89. Retrieved from www.sworld.com.ua/konfer31/929.pdf

13. Novikova, I. N., Popova, L. G., Shatilova, L. M., Biryukova, E. V., Guseva, A. E., \& Khukhuni, G. T. (2018). Lexical and semantic representation of the linguistic and cultural concept "Rest" in the English, German, and Russian languages. Opción, 34(85-2), 237-256.

14. Ovsyannikova, V.V. (2012). Features of the syndrome of burnout in the faculty of higher education. Problemi suchasnoi psihologii, no 1.113-118. Retrieved from http://nbuv.gov.ua/UJRN/pspz_2012_1_22 
15. Antoniou, A.S., Polychroni, F. \& Vlachakis, A.N. (2006). Gender and age differences in occupational stress and professional burnout between primary and high-school teachers in Greece. Journal of Managerial Psychology, no 21 (7), 682-690. https://doi.org/10.1108/02683940610690213

16. Aouil, B., Leźnicka, M., Jachimowicz-Wołoszynek, D. \& Zaremba, J. (2011). Narażenie na ryzyko wypalenia zawodowego a skłonność do zgłaszania się po pomoc psychologiczną. Hygeia Public Health, no 46(3), 339-354.

17. Goddard, R. \& Goddard, M. (2006). Beginning Teacher Burnout in Queensland Schools: Associations with Serious Intentions to Leave. Researcher, no 33 (2), 61-75. Retrieved from https://files.eric.ed.gov/fulltext/EJ766609.pdf. https://doi.org/10.1007/BF03216834

18. Orel, V.E. (2001). The phenomenon of "burnout" in foreign psychology: empirical research and prospects. Psikhologicheskiy zhurnal, no 1(22). 90-101.

19. Zborovskaya, I.V. (2001). Self-regulation of mental stability of the teacher. Prikladnaya psikhologiya, no 6. 55-65.

20. Practical psychodiagnostics. Methods and tests. (1998). Samara: Publishing House "Bakhrakh".

21. Trunov, D.G. (1998). "Combustion Syndrome": a positive approach to the problem. Journal of practical psychologist, no8. 84-89.

22. Formalyuk, T.V. (1994). The syndrome of "emotional combustion" as an indicator of professional teacher maladjustment. Voprosy psikhologii, no 6. 57-64.

23. Gnezdilov, A.V. (2004). Psychology and psychotherapy of loss. St. Petersburg: Publishing House "Rech".

24. Boyko, V.V. (1996). Emotion energy in communication: a look at yourself and others. Moscow: Informats. Ed. House Owl.

25. Iravani, M. R., Niknejadi, F., \& Jahandoost, Z. (2015). The Relationship Between Age And Job Satisfaction Consultants Government Girls High School In Isfahan In 2012-2013 Academic Year. Health, 70(22.65), 24.

26. Pak, S.N. (2016). The main aspects of the professional teacher burnout syndrome. Sovremennyye problemy nauki $i$ obrazovaniya, no 6.

27. Mituzova, M.P. (2011). Burnout syndrome teachers. Moscow: "The First of September".

28. Yanovskaya, N. (2009). Teacher emotional burnout. Narodnoye obrazovanie, no 2.

29. Vodopyanova, N.E. (2009). Stress psychodiagnosis. St. Petersburg: Piter.

30. Swartzer, K. (2018). The Causes of Teacher Burnout: What Everyone Needs to Know.

31. Seidel, A. (2014). The teacher dropout crisis. NPR. Retrieved from http://www.npr.org/blogs/ed/2014/07/18/332343240/the-teacher-dropoutcrisis?utm campaign=storyshare\&utm_source=twitter.com\&utm_medium=social

32. Suleri, J., \& Cavagnaro, E. (2016). Promoting pro-environmental printing behavior: The role of ICT barriers and sustainable values. International Journal of Education and Development using ICT, 12(2). https://doi.org/10.20897/lectito.201638

33. Koç, Hakan \& Dinçerol, Cem. (2013). A Study Professional and Job Burnout on Teachers.

34. Alkhateeb1, O., Kraishan, O. M., \& Salah, R. O. (2015, May 27). Level of psychological burnout of a sample of secondary phase teachers in Ma'an Governorate and its relationship with some other variables. International Education Studies, 8(6), 56-68. https://doi.org/10.5539/ies.v8n6p56

35. American Institutes for Research (AIR). (2013). Most teachers "highly qualified" under NCLB standards, but teacher qualifications lag in many high poverty and high minority schools. Retrieved from http://www.air.org/reports-products/index.cfm?fa=viewContent\&content_id=417

36. Fujo, M. H., \& Dida, M. A. (2019). Centralized Admission System for Advanced Level Private Schools: Case of Kilimanjaro Region, Tanzania. Journal of Information Systems Engineering \& Management, 4(1). https://doi.org/10.29333/jisem/5743 Bill and Melinda Gates Foundation (2014). Primary sources: America's teachers on teaching in an era of change: A project of Scholastic and the Bill and Melinda Gates Foundation (3rd ed.). Retrieved from http://www.scholastic.com/primarysources/download-the-full-report.htm 